\title{
Procedural Bio-Medical Waste Management - A Comparison with International Standards
}

\author{
Dr.B. Rajeswari
}

\begin{abstract}
Though India has the state of art medical facilities on par with global standards for a comparatively cheaper cost with best knowledge, the bio-waste management protocols of many hospitals are far below the international standards. An effort was made to understand the bio-waste management procedures of big hospitals by making a critical analysis of bio waste generated. Biomedical waste includes syringes, live vaccines, laboratory samples, body parts, bodily fluids and waste, sharp needles, cultures and lancets. Based on the parameters of number of beds occupied and number of operations performed on any single day of the observation period of 30 days and comparing with the International Standards mentioned by World Health Organization, an analysis was made to understand whether the hospitals are following the quality parameters implemented by them. After 30 days of evaluation of biomedical waste management protocol at B.L Kapur hospital, New Delhi, it is found that the amount of hazardous bio-medical waste generated/bed/day exceeds the limit as per the international standards. For this study, the labeling component of the protocol for waste management for various departments was documented, to understand the protocol adopted. Through analysis it is concluded that to avoid hazardous effects, all major hospitals should seriously train their staff about the perilous effects of bio-waste and segregating and labeling them properly for disposal by launching a waste management protocol. It is also suggested that by recording the amount of general waste as well as bio-waste generated and conducting periodical surveillance of health care waste management practices, the hospitals can help the hospitals in protecting the environment. As it is an area of much concern, further studies can also be made to understand the impact of such negligible way of handling bio-medical wastes and the impact of such acts on the community.
\end{abstract}

Keywords--- Bio-Medical Waste, Critical Analysis, Hazardous, International Standards, Protocol, Surgeries

\section{INTRODUCTION}

I NDIA as an emerging preferred destination for health care 1 due to its proficiency in Traditional as well as Modern system of Medicines and deliberate caring for the patients is infested with bio medical waste management issues. It is also

Dr.B. Rajeswari, Assistant Professor, Department of Management Studies, School of Management, Pondicherry University, Pondicherry-605 014.India.E-mail:raajeebster@gmail.com

DOI: 10.9756/BIJIEMS.3027 well known for its state of art medical facilities especially in metro cities like New Delhi, Mumbai and Chennai, on par with global standards and comparatively for a cheaper cost with best knowledge. Not only the hospitals but also Government regulatory machineries and also the public always turn a blind eye to bio medical waste management protocol of many major hospitals which are producing more wastages than the allowed International standards announced by WHO [1]for developing countries. In contrast to its positive side of being a better medical facility provider, the other side of health care especially the bio-medical waste management has been neglected which is considered potentially hazardous [2]. Sorting of medical wastes in hospital, at the site where it is generated and disposing them by using specially labeled bags and containers by specially designed biomedical waste transporters. Other forms of waste should not be mixed with biomedical waste as different rules apply to the treatment of different types of waste. The biomedical waste if disposed of untreated can pose a huge risk to the health of the public, professionals, patients and environment. Delivery of patient care services is the responsibility of healthcare facilities and hospitals as waste is generated in the process of delivering these healthcare facilities [3]. The process of waste generation, handling and management is important for the health of everyone. Biomedical waste differs from other types of hazardous waste, such as industrial waste, in that it comes from biological sources or is used in the diagnosis, prevention, or treatment of diseases. Common producers of biomedical waste include hospitals, health clinics, nursing homes, medical research laboratories, offices of physicians, dentists, and veterinarians, home health care, and funeral homes. Though many hospitals claim that, they have stringent bio-medical waste management amenities, the reality is that, they are not following any of the International standards suggested by World Health Organization.

\section{i. $\quad$ Health Impacts of Bio-Medical Wastes}

Improper disposal of bio-medical waste can be very hazardous and can lead to high degree of environmental pollution and can pose serious risk to public health. Biomedical waste, also known as infectious waste or medical waste is defined as waste generated during the diagnosis, testing, treatment, research or production of biological products for humans or animals. Biomedical waste includes syringes, live vaccines, laboratory samples, body parts, bodily fluids and waste, sharp needles, cultures and lancets. The hospital management should get into an agreement with Municipal Corporation in developing and implementing eco friendly method of treating the wastes generated like this [4]. 
Poor management of hospital waste can lead to following diseases

- $\quad$ HIV positive

- Hepatitis B and C

- Respiratory infections

- Skin infections

- Radioactive toxicity

- Health problems due to air and water pollution

ii. Untreated Bio-Medical Waste can also lead to Environmental Problems like

1. Foul odor may be generated by decomposing waste in the hospital and surrounding area.

2. Dumping of hospital waste may attract stray animals and birds leading to spreading of waste that might make the environment unhygienic.

3. Drains may be blocked due to waste materials leading to unhygienic environment and breeding of mosquitoes and flies.

4. Discharge of untreated waste water can have disastrous ecological effects.

5. There is an unrecognized training need exists about educating the people towards understanding the problems related to mismanagement of hospital wastes. [5].

iii. Objectives

- To determine the amount of waste generated per bed per day

- To compare the amount of waste generated per bed per day with the international standards.

- To document the labeling component of the protocol for waste management.

- To suggest possible remedial measures if required.

iv. Profile of the Hospital

- Dr.B.L. Kapur, M.D. (Germany), an eminent Obstetrician and Gynecologist, set up a charitable Hospital in 1930 at Lahore Pakistan. In 1947, Dr.B.L. Kapur moved to post-partition India and set up a maternity hospital at Ludhiana Punjab.

- In 1956, on the invitation of then Prime Minister, Dr.B.L. Kapur initiated the project for setting up a two hundred bed hospital in Delhi. The hospital was inaugurated by the Prime Minister, Pt.Jawahar Lal Nehru on $2^{\text {nd }}$ January 1959.

- In late 1990s, the Trustees of the hospital felt the need to upgrade it to a tertiary care hospital, keeping in view the present day requirements of the society. A modern state of the art tertiary care hospital has come up in the place of the old hospital.

\section{v. Quality Parameters}

- The hospital has been designed for maximum safety and comfort of the patients and healthcare providers. It complies with national and international standards for hospital accreditation.

- Clinical governance is an integral part of our practice.
- Robust quality and infection control practices are in place.

- Best in class modular OT`s and ICU`s with HEPA filters, laminar air flow and 20 complete air changes per hour and access control minimize the risk of infection.

- Isolation rooms have been earmarked in the ICU to treat critically ill infectious patients thus preventing threat to other patients.

- Stringent "Biomedical Waste Management" practices for segregation, storage, transport and disposal of hospital waste are in place.

- Green building: The hospital is designed to allow sunlight in most of the ICU`s and patient rooms as it minimize stress on the patients and gives them proper orientation of time.

- The hospital has one of the most advanced "Building Management Systems" which help in patient and employee safety and reduce the excessive burden on the infrastructure and environment.

- Delhi`s first automated pneumatic chute system for immediate transfer of samples, medicines and documents minimizing delays and ensuring safe and hygienic transfer.

- The "Hospital Information System" used is most advanced and user friendly and helps to reduce medical errors as well as contributes to faster and better patient management [6].

\section{vi. $\quad$ Significance of the Study}

Since bio-medical wastes are hazardous to the nature, the Hospitals should keep focus on reduction of generating biomedical waste. For this purpose some International standards are there, but whether Indian hospitals are following or not is a question. To understand the situation, an effort was made to study the protocol for waste management in one of the popular hospitals in New Delhi. This can be achieved by maintenance of a system that relies on reprocessing and reuse of materials. If we have clear guidelines for product purchasing that emphasizes waste reduction will keep waste management problems in focus. We need to put new emphasis on waste reduction of hazardous materials. It is understood that, the staff of different categories are to be trained and educated about the management of biomedical waste. Also there is a need for secure internal and external collection and transportation systems for the waste. As per the policies, the hospitals have to waste is segregate the wastes at the point of generation and secure in separate containers for ultimate disposal. But in reality everything is mixed up by municipal workers upon a single collection then the ultimate value is lost [7].

\section{NEED FOR THE STUDY}

\section{i. Occupational Safety}

Nurses, Auxiliary Nurse Midwives (ANMs), health care workers and recyclers can suffer from needle stick injuries. This can happen either just after the injection has been administered, during the disposal of the used syringe or even after disposal to those involved in recovering them. Of all the 
potential sources of infection transmission from bio-medical waste, needle sticks are of prime concern to the Health staff and the community at large [8].

\section{ii. $\quad$ Re-use Potential}

In India, the sale of used, superior quality non AD syringes is lucrative. Therefore, there is a potential risk of illegal reuse, posing a risk to the entire community. The process of re-use of syringes involves a chain of recovery of intact and unmutilated syringes, cursory cleaning in appearance, in some cases repacking, and reentrance on to the user chain. Clean looking syringes are known to command a higher price in the recycling market than mutilated ones, supporting the fear of their intrinsic public health risk.

\section{iii. Safe Disposal}

Used syringes need to be disposed of in an environmentally safe and pollution-free manner. Often, plastic syringes that contain polyvinyl chloride (PVC) are incinerated. Dioxins and furans and other toxic air pollutants are produced as emissions and/or bottom fly ash. Exposure to dioxins and furans leads to significant adverse health effects. To ensure safe disposal, recycling after disinfection and mutilation or containment in pits are the possible options. Any solution to handle sharps waste needs to encompass all three concerns and keep in mind the environmental and human health perspectives. The issue assumes added importance due to the quantum of waste generated from immunization programmes. In the context of developing countries, the nature of immunization programmes delivery in poorly equipped primary health centers scattered across the countryside or through door-to-door service provided by grassroots workers such as ANMs requires a simple, workable and affordable sharps management system[9]. As an example, if the ANM is required to carry back the used syringe from the village back to the primary or the district health centre, adequate storage needs to be available.

\section{Methodology OF THE Study}

- The study was conducted at B.L Kapur Memorial hospital for a period of 30 days.

- Method of disposal of bio-medical waste at the central garbage repository was studied by direct observation.

- Bio-medical waste was segregated as :

Blue bags for plastic disposable waste

Yellow bags for incinerable waste

Puncture proof containers for collection of sharp items.

They all had Bio-hazard Emblem printed on them as suggested for safe handling and management of bio wastes[10].

- Every day, the Synergy worker was asked to weigh all the bags with a weighing scale and the amount of waste generated from different areas was recorded. Bags without labeling were weighed separately and their weights were documented under the category of unlabeled bags.

- Informal discussion with housekeeping supervisor and synergy workers was carried out.
- $\quad$ The data on bed occupancy and number of surgeries for each day during the 30 days of survey was also collected.

\section{DATA ANALYSIS}

To understand the bio-waste management protocol a critical analysis is made to understand the bio-waste generated by the hospital, number of beds occupied and number of operations performed on any single day of the observation period of 30 days. Then these things are compared with the International Standards mentioned by WHO to decide whether the hospital is following the quality parameters developed by themselves.

In bio-waste management segregating and labeling are important to identify the type of bio-waste, so that disposal methods can be decided [11].

\section{i. Calculation of the Amount of Waste Generated per bed per day}

It was calculated for each day by using the formula:

Amount of waste generated/bed/day =

Amount of waste generated on that day (Blue+Yellow+Sharp) / Bed occupancy on that day.

The number of surgeries for each day during the 30 days of survey was documented on a daily basis so that we can correlate the amount of waste generated with the number of surgeries performed on that day.

Table 1: Amount of Waste Generated/Bed/Day

\begin{tabular}{|c|c|c|c|c|c|}
\hline Days & $\begin{array}{c}\text { Waste } \\
\text { generated } \\
\text { /bed/day } \\
{[\mathrm{kg}]}\end{array}$ & $\begin{array}{l}\text { No.of } \\
\text { Surge } \\
\text { ries }\end{array}$ & $\begin{array}{c}\text { Day } \\
\text { s }\end{array}$ & $\begin{array}{c}\text { Waste } \\
\text { genered } \\
\text { bed/day[ } \\
\text { kg }\end{array}$ & $\begin{array}{c}\text { No. of } \\
\text { Surgerie } \\
\text { s }\end{array}$ \\
\hline 1 & 0.9 & 16 & 16 & 0.61 & 17 \\
\hline 2 & 0.67 & 16 & 17 & 0.59 & 2 \\
\hline 3 & 0.71 & 13 & 18 & 0.798 & 17 \\
\hline 4 & 0.63 & 11 & 19 & 0.69 & 15 \\
\hline 5 & 0.97 & 19 & 20 & 0.59 & 14 \\
\hline 6 & 0.84 & 16 & 21 & 0.89 & 19 \\
\hline 7 & 0.74 & 18 & 22 & 0.77 & 16 \\
\hline 8 & 0.65 & 16 & 23 & 0.61 & 14 \\
\hline 9 & 0.82 & 15 & 24 & 0.73 & 17 \\
\hline 10 & 0.68 & 15 & 25 & 0.87 & 18 \\
\hline 11 & 0.45 & 17 & 26 & 0.81 & 20 \\
\hline 12 & 0.78 & 12 & 27 & 0.64 & 17 \\
\hline 13 & 0.65 & 18 & 28 & 0.85 & 16 \\
\hline 14 & 0.60 & 15 & 29 & 0.67 & 13 \\
\hline 15 & 0.46 & 22 & 30 & 0.66 & 21 \\
\hline & \multicolumn{5}{|c|}{ Average $=0.71$} \\
\hline
\end{tabular}

Source: Primary data

As per the tabulated information from Table-1, the average bio medical waste generated for the observed period of 30 days is $0.71 \mathrm{~kg}$ which is above the International standard of 0.3 kgs according to the suggestion of World Health Organization. 


\section{ii. $\quad$ Comparing the Amount of Bio-Medical waste Generated/bed/day with the number of Surgeries occurring in that day}

The number of surgeries for each day during the 30 days of survey was documented on daily basis so that we can correlate the amount of waste generated with the number of surgeries performed on that day

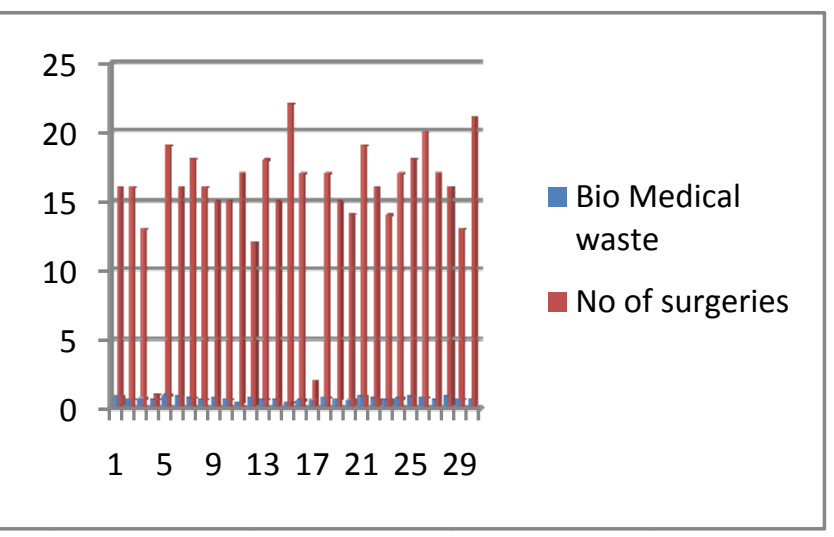

Figure 1: Comparison of amount of bio-medical waste generated/bed/day with the number of surgeries Source: Primary data.

The $\mathrm{h}$ I, about the comparison between the biomedical waste generated with that of number of surgeries, illustrates that we cannot correlate the amount of bio-medical waste generated/bed/day with the number of surgeries performed on that day because even when the number of surgeries are very few on day 4 and day 30 but still the amount of waste generated is on the higher side.

Amount of bio-medical waste generated when the number of surgeries is just 1 on day $4=0.63 \mathrm{Kg}$

Amount of bio-medical waste generated when the number of surgeries performed are the maximum i.e. 22 on day $15=$ $0.46 \mathrm{~kg}$, so there is no significant correlation between the amount of bio-medical waste generated/bed/day and the number of surgeries performed on that day.

iii. Calculation of Percentage Variation of Waste Generated per bed per day as per WHO standards

As per WHO standards, amount of hospital waste generated/bed/day $=1.5-2.5 \mathrm{Kg}$

Out of which, Bio-medical waste $=15 \%$ of $1.5-2.5 \mathrm{Kg}$

Mean of $1.5-2.5 \mathrm{Kg}=2 \mathrm{Kg} \quad$ So, $15 \%$ of $2 \mathrm{Kg}=0.3 \mathrm{Kg}$
Table 2: Percentage Variation Of Waste Generated Per Bed Per Day As Per Who Standards

\begin{tabular}{|c|c|c|c|c|c|c|c|}
\hline $\begin{array}{c}\text { Day } \\
\text { s }\end{array}$ & $\begin{array}{c}\text { Waste } \\
\text { genera } \\
\text { ted } \\
\text { /bed/d } \\
\text { ay } \\
{[\mathrm{kg}]}\end{array}$ & $\begin{array}{c}\text { Stan } \\
\text { dard } \\
\text { wei } \\
\text { ght }\end{array}$ & $\begin{array}{c}\% \\
\text { increase } \\
\text { Or } \\
\text { decrease }\end{array}$ & $\begin{array}{l}\text { Da } \\
\text { ys }\end{array}$ & $\begin{array}{c}\text { Waste } \\
\text { generate } \\
\text { d/ } \\
\text { bed } \\
\text { /day }\end{array}$ & $\begin{array}{l}\text { Stan } \\
\text { dard } \\
\text { wei } \\
\text { ght }\end{array}$ & $\begin{array}{c}\% \\
\text { increase } \\
\text { or } \\
\text { decrease }\end{array}$ \\
\hline 1 & 0.9 & 0.3 & 4200 & 16 & 0.61 & 0.3 & † 103 \\
\hline 2 & 0.67 & 0.3 & 4123 & 17 & 0.59 & 0.3 & 4 96 \\
\hline 3 & 0.71 & 0.3 & $\uparrow 136$ & 18 & 0.79 & 0.3 & $\begin{array}{ll}\uparrow & 163\end{array}$ \\
\hline 4 & 0.63 & 0.3 & 个 110 & 19 & 0.69 & 0.3 & 个 130 \\
\hline 5 & 0.97 & 0.3 & 4223 & 20 & 0.59 & 0.3 & $\begin{array}{ll}\mathbf{4} & 96\end{array}$ \\
\hline 6 & 0.84 & 0.3 & 180 & 21 & 0.84 & 0.3 & $\begin{array}{ll}\boldsymbol{\uparrow} & 180\end{array}$ \\
\hline 7 & 0.74 & 0.3 & 146 & 22 & 0.82 & 0.3 & $\begin{array}{ll}\uparrow & 173\end{array}$ \\
\hline 8 & 0.65 & 0.3 & 4116 & 23 & 0.69 & 0.3 & $\begin{array}{ll}\mathbf{A} & 130\end{array}$ \\
\hline 9 & 0.82 & 0.3 & 4 173 & 24 & 0.97 & 0.3 & $\begin{array}{ll}4223 \\
\end{array}$ \\
\hline 10 & 0.68 & 0.3 & 4126 & 25 & 0.68 & 0.3 & $\begin{array}{ll}4 & 126\end{array}$ \\
\hline 11 & 0.45 & 0.3 & 450 & 26 & 0.78 & 0.3 & 4 160 \\
\hline 12 & 0.78 & 0.3 & 4160 & 27 & 0.60 & 0.3 & $\begin{array}{ll}\boldsymbol{4} & 100\end{array}$ \\
\hline 13 & 0.65 & 0.3 & 4 116 & 28 & 0.46 & 0.3 & 4 53 \\
\hline 14 & 0.60 & 0.3 & 个 100 & 29 & 0.45 & 0.3 & $\uparrow \quad 50$ \\
\hline 15 & 0.46 & 0.3 & 453 & 30 & 0.68 & 0.3 & $\begin{array}{ll}\mathbf{4} & 126\end{array}$ \\
\hline
\end{tabular}

Source: Primary data

According to Table 2, about the variation we can easily understand about the percentage increase in the biomedical waste generated per bed per day when compared with the International standard weight of $0.3 \mathrm{kgs}$. The percentage increase is in the range of $50 \%$ to a maximum of $223 \%$ which shows the level of violating the International standards.

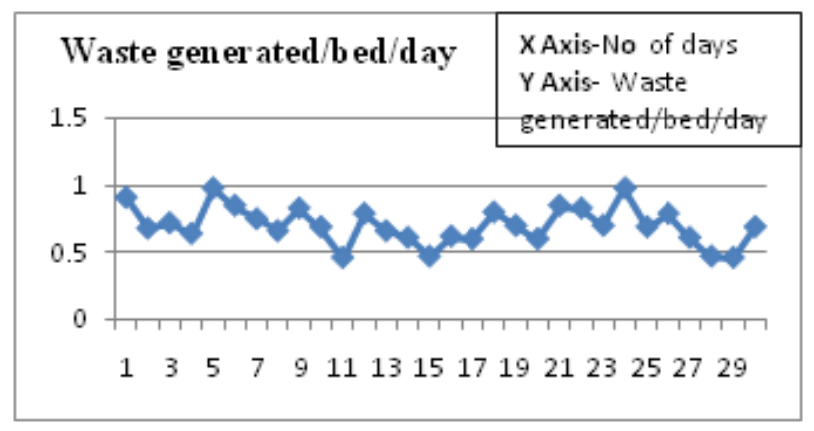

Figure 2: Amount of bio-medical waste generated/bed/day Source: Primary data.

The figure 2, which is about the amount of bio-wate generated per bed per day, clearly shows the different levels of the bio-medical waste generated by the hospital during the days of observation.

- Maximum waste generated by the hospital in these 30 days was $-0.97 \mathrm{Kg}$ 
- Minimum waste generated by the hospital in these 30 days was $-0.45 \mathrm{Kg}$

- Even the minimum waste generated/bed/day is beyond the acceptable limits.

iv. Comparison of the amount of bio-medical waste generated per bed per day with the international standards:

As per WHO standards, amount of hospital waste generated/bed/day $=1.5-2.5 \mathrm{Kg}$

Out of which, Bio-medical waste $=15 \%$ of $1.5-2.5 \mathrm{Kg}$

According to international standards, $\mathrm{BMW}=0.3 \mathrm{Kg}$

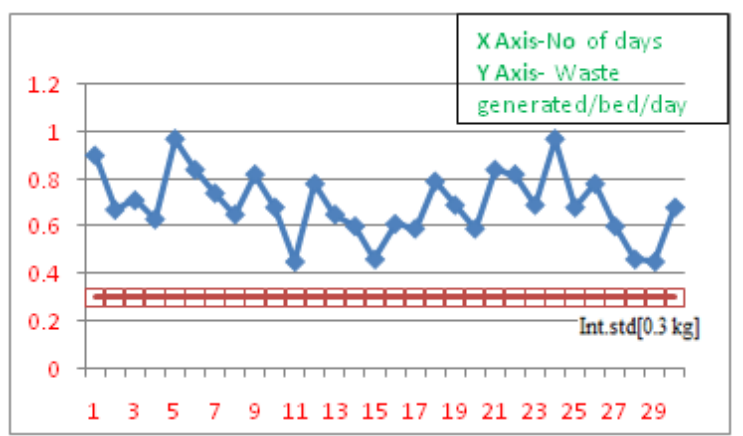

Figure 3: Comparison of amount of bio-medical waste generated/bed/day compared with International standard

As per figure 3, it is obviously understood that the amount of bio-medical waste generated/bed/day clearly exceeds the limit as per the international standards on almost all days of observation.

The maximum increase in percentage of bio-medical waste generation above the level of set international standards $(0.3$ $\mathrm{kg} /$ bed/day) is by $223 \%$

The minimum increase in percentage of bio-medical waste generation above the level of set international standards (0.3 $\mathrm{kg} / \mathrm{bed} /$ day) is by $50 \%$

There's never been a decrease in the percentage of biomedical waste generation below the set international standards (0.3 kg/bed/day)

\section{v. Documentation of Labeling Component of the Protocol for Waste Management}

The amount of waste generated from different areas was documented separately under three different categories - blue, yellow and sharp. Bags without labeling were weighed separately and their weights were documented under the category of unlabeled bags as suggested.

The next figure number 4 which is about the number of days, for which labeled 'Blue bags' which are specifically meant for collecting plastic disposable waste found, clearly shows that the areas which were continuously labeled properly throughout the entire duration of the study were:

- O.T (Occupational therapy)

- $\quad$ MICU (Medical Intensive Care Unit)

- BMT (Bone Marrow Transplant)
These 3 departments showed properly labeled bags on all 30 days, whereas the hematology department which takes care of blood related diseases, the blood-forming organs, and blood diseases showed least number of labeled bags in 30 days. Only 2 labeled bags were found from this department throughout the entire duration of the study.

Similarly the amount of waste generated in labeled yellow bags which are specifically meant for collecting incinerable waste from all the departments was documented for a period of 30 days. 


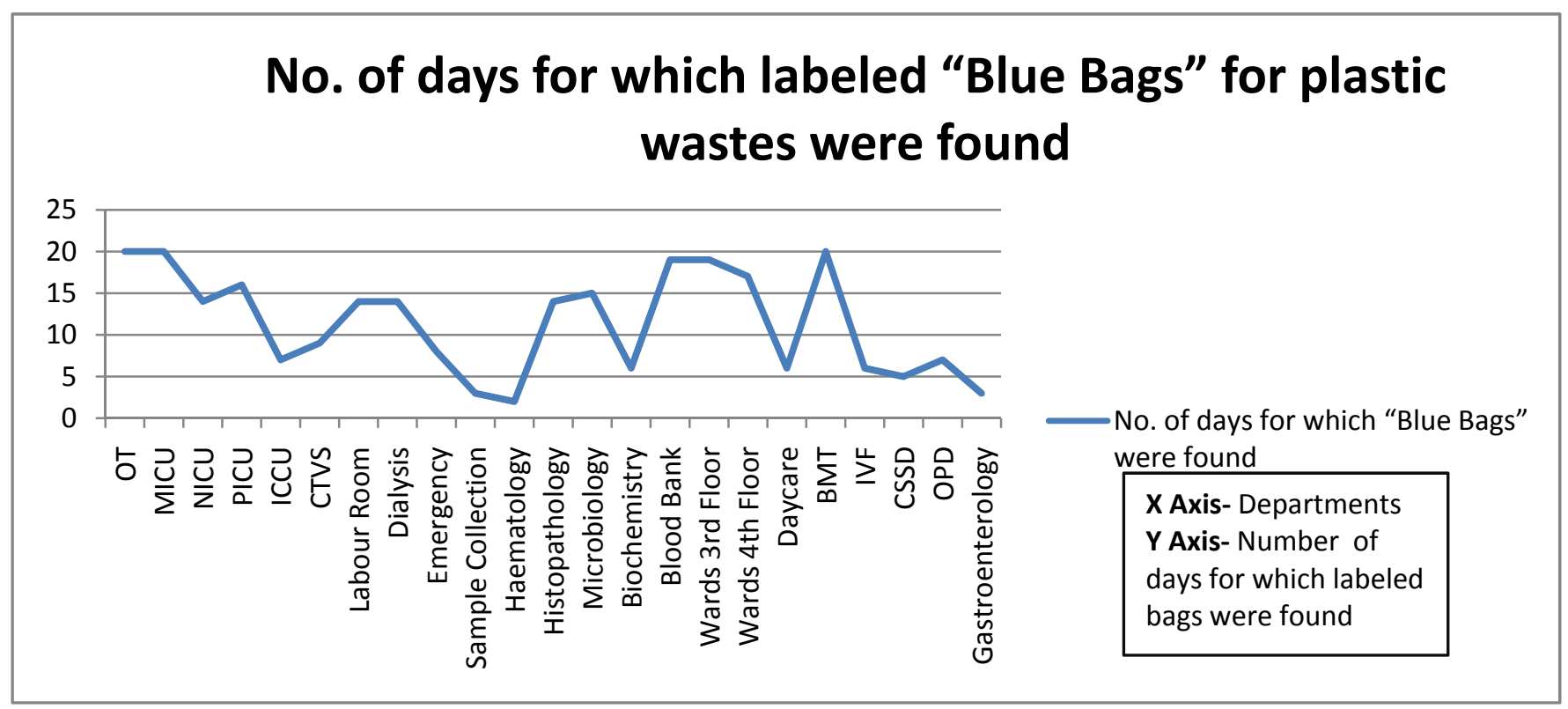

Figure 4: Number of Days which Blue Bags were found

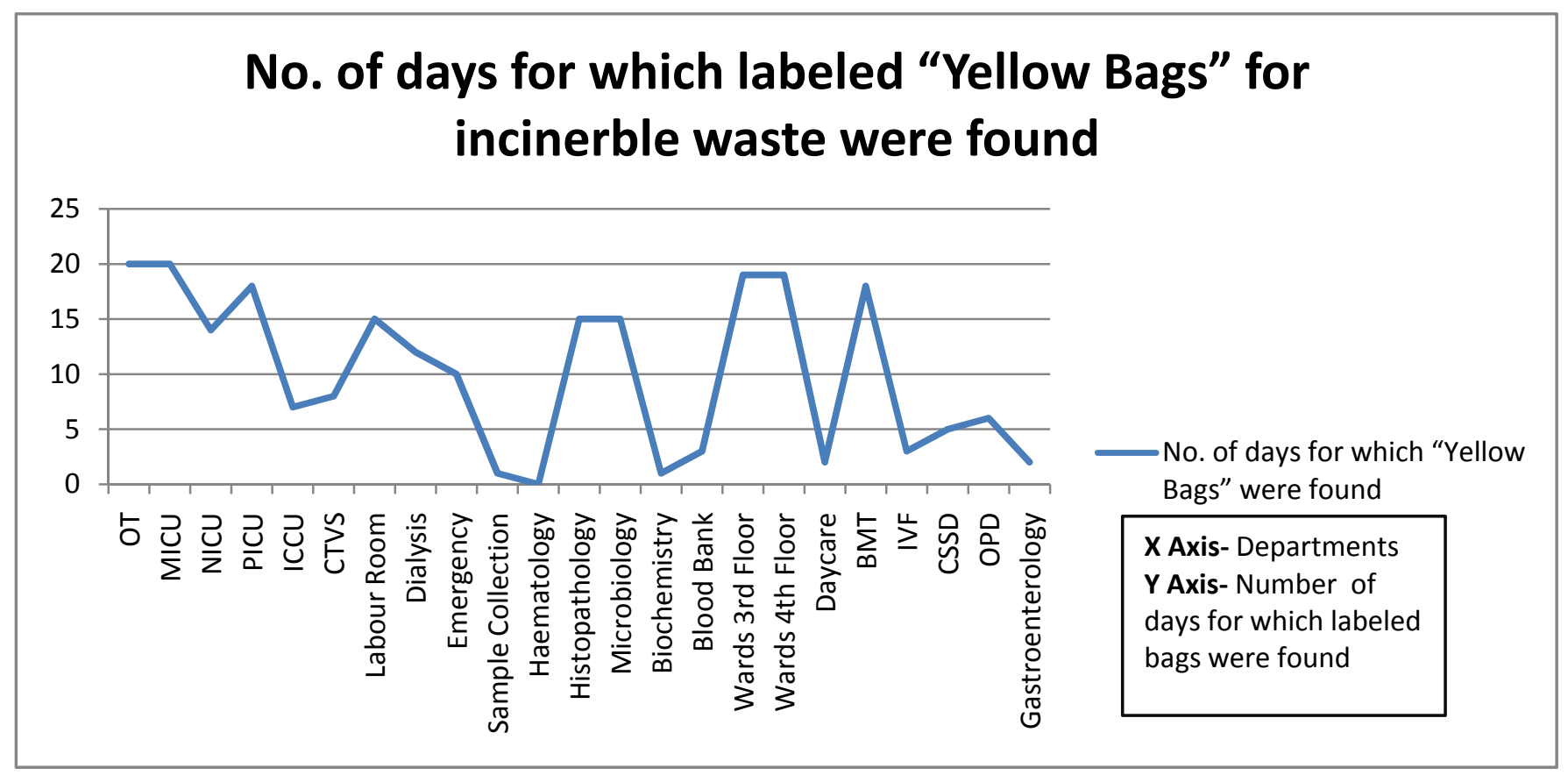

Figure 5: Number of Days which Yellow Bags were found

The figure 5, which is bout labeled yellow bags clearly shows that the areas which were continuously labeled properly throughout the entire duration of the study were:

- $\quad$ O.T (Occupational therapy)

- $\quad$ MICU (Medical Intensive Care Unit)

These two departments showed properly labeled yellow bags on all 30 days, whereas the hematology department did not show any labeled yellow bag in 30 days. The Sample Collection department also showed just 1 yellow bag during the entire duration of the study. vi. Findings

- The average bio medical waste generated for the observed period of 30 days is $0.71 \mathrm{~kg}$ which is above the international standards.

- When number of surgeries performed on that day is correlated with the amount of waste generated, it is found that there is no significant correlation as even when the number of surgeries are very few on day 4 and day 17 still the amount of waste generated is on the higher side.

- As per WHO standards, amount of hospital biomedical waste generated/bed/day is $0.3 \mathrm{~kg}$, but the 
bio-medical waste generated by the hospital is exceeding the standard limit; even the minimum waste generated/bed/day is beyond the acceptable limits $(0.45 \mathrm{Kg})$

- The amount of bio-medical waste generated/bed/day clearly exceeds the limit as per the international standards, as maximum increase in percentage is $223 \%$ and minimum increase in percentage is $50 \%$.

- There's never been a decrease in the percentage of bio-medical waste generation below the set international standards ( $0.3 \mathrm{~kg} / \mathrm{bed} /$ day $)$

- Out of 23 departments generating bio-medical waste only three departments properly labeled blue bags on all 30 days (plastic disposable waste).

- The hematology department which takes care of blood related diseases and blood-forming organs showed least number of blue labeled bags in 30 days.

- Out of 23 departments generating bio-medical waste only two departments properly labeled yellow bags on all 30 days (incinerable wastes).

- The hematology department did not show any labeled yellow bag in all observed 30 days.

\section{vii. Suggestions}

- Staff training and awareness underpin several of the short and medium/ long term solutions should be suggested to reduce the waste at source.

- Staff should be seriously trained about the hazardous effects of bio-waste and segregating and labeling them properly for disposal [12].

- Possibilities of recycling to be explored in a scientific and hygienic manner for permissible items.

- The documentation of the amount of waste generated per day should be supervised by the housekeeping supervisor.

- The amount of general waste generated by the hospital should also be recorded.

- Periodical surveillance of health care waste management practices should be conducted.

- Information with respect to risks involved in health care waste management practices have to be disseminated, for public or general community [13].

\section{CONCLUSION}

After 30 days of evaluation of biomedical waste management protocol at B.L Kapur hospital, it is found out that the amount of bio-medical waste generated/bed/day exceeds the limit as per the international standards and only a few departments have properly labeled waste bags. It is shocking to know that a popular hospital with all facilities in a metropolitan like New Delhi itself is not able to follow the International standards; nothing can be said about the number of hospitals functioning throughout India. It is high time to look into such matters to improve the hygienic living conditions within India. Further studies can also be made to understand the impact of such negligible way of handling biomedical wastes and the impact of such acts on the community.

\section{REFERENCES}

[1] World Health Organization, "Safe Management of Wastes from Health Care Activities", convention, Geneva,1999.

[2] Fred A. Curtis and Karen Mak, "A Medical Waste Management Strategy", Environmental Management and Health, Vol. 2 No. 1, Pp.13 $-18,1991$.

[3] Ministry of Environment and Forests, New Delhi "Bio-Medical Wastes (Management and Handling) Rules", 1997-98 notified on $16^{\text {th }}$ October and Gazetted on 27 October 1997, 20 $0^{\text {th }}$ July 1988.

[4] Hema Chandra, "Hospital Waste - An Environmental Hazard and its Management", ISEB Vol. 5. No.3, July, 1999.

[5] Veda Hegde, RD Kulkarni and GS Ajantha,"Biomedical Waste Management”, Journal of Oral and Maxillofacial Pathology, Vol 11, No.1,Pp. 5-9, 2007.

[6] Sister June Caroline, Manual on Bio-medical waste management, Dr. B.L Kapur memorial hospital manual on Bio-medical waste management, 2009.

[7] G.V. Patil and K. Pokhrel, "Biomedical solid waste management in an Indian hospital: a case study", Waste Management, Vol. 25 Pp.592-9, 2005.

[8] R.N. Basu“ Issues involved in Hospital Waste Management; an experience from a large teaching institution”, Journal of Academy of Hospital Admimstration. No. 101, Pp.79-83, 1995.

[9] G. Baveja, S. Muralidhar and P. Aggarwal, "Hospital waste management - an overview", Hospital Today, Vol. 5 No.9, Pp.485-6, 2000.

[10] A. Prüss, E. Giroult and P. Rushbrook, "Safe Management of Wastes from Health-Care Activities Handbook", World Health Organisation, Geneva, 1999.

[11] A.D. Patil, and A. Shedkar, "Health care waste management in India", Journal of Environmental Management, Vol. 63 No. 2, Pp. 211-20, 2001.

[12] R. Singh and S.L. Mahajan " Management of Hospital Waste in Hospitals of Govt. Medical College, Amritsar", Journal of Academy of Hospital Administration, No.1, Pp.33-37, 1998.

[13] M.D. Qureshi Waseem, DHA; G. Hassan MD; Baba MS; S.M. Kadri MB and Khan Nazir MS., "Awareness of Biomedical Waste Management amongst staff of the Government S.M.H.S Hospital, Srinagar. K- Practitioner”; No.14 (1), Pp.60-61.

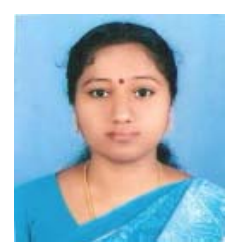

Dr.B. Rajeswari, born in Tamilnadu, India on 18.07.1970.

Graduated from Tamilndu Agricultural University with B.Sc in Agriculture and MBA from Madurai Kamaraj University of Madurai. She pursued her doctorate in Management from Gandhigram Rural University ,Gandhigram- Dindigul, Tamilnadu.. Having 11 years of teaching experience from various institutions in Tamilnadu and currently working as an Assistant Professor in School of Management of Pondicherry University.

Author can be contacted at raajeebster@gmail.com 